\title{
Quality Management System in Medical Laboratory Practice: Knowledge and Perceptions of Medical Laboratorians in Saudi Arabia
}

\author{
Abdulraheem Almalki* \\ Department of Clinical Laboratory Sciences, College of Applied Medical Sciences, \\ Taif University, Al-Taif, Saudi Arabia \\ *Corresponding Author: Abdulraheem Almalki, Department of Clinical \\ Laboratory Sciences, College of Applied Medical Sciences, Taif University, Al-Taif, \\ Saudi Arabia.
}

Received: November 08, 2020

Published: November 27, 2020

(C) All rights are reserved by Abdulraheem

Almalki.

\begin{abstract}
Medical laboratorians play an important role in clinical and public health settings by providing test results. The quality of the testing process has a major impact on health outcomes. This study aimed to measure the knowledge and perceptions of laboratorians employed in Saudi Arabia. A cross-sectional study was conducted with laboratorians working at different hospitals using a previously published and validated questionnaire through a social media application. A total of 263 laboratorians completed the questionnaire. The majority of participants were specialists with fewer than 5 years of experience. In general, laboratorians were shown to be knowledgeable. The majority agreed that the level of education, the number of years of experience, the professional credentials and the turnover rate of positions had a significant impact on quality assurance objectives. In conclusion, laboratorians need to be trained about quality systems and encouraged to have a role to ensure the highest level of service.
\end{abstract}

Keywords: Quality System; Quality Control; Quality Assurance; Laboratory Professionals

\section{Abbreviation}

QA: Quality Assurance

\section{Introduction}

Medical laboratorians play an important role in clinical and public health settings by providing test results for patients that help in the diagnosis and treatment of many diseases. The testing process is a complex process that involves many steps and personnel and the use of a wide variety of techniques with varying degrees of complexity and difficulty. The quality and accuracy of the testing process are important and have a major impact on the health outcomes because errors may significantly affect patient health. In any measurement, a degree of uncertainty is normally expected for various reasons. Thus, it is important to attain a high level of accuracy and reliability in all steps and activities in the testing process [1].
A quality management system (QMS) is defined as "coordinated activities to direct and control an organization with regard to quality" [2]. In a laboratory, this is related to the analytical phase and all its steps and operations are well controlled and the results reported are as accurate as possible, reliable and reported at the right time to be useful in clinical and public health settings. Various standard and organizations such as ISO9001 and the Clinical and Laboratory Standards Institute (CLSI) [3] have established standards and guidelines to help laboratories to implement a QMS [4]. In addition, most laboratories often generate their own system of internal standards and policies to enhance quality. The purpose of a QMS in a laboratory is to improve the quality and safety of testing and subsequently to promote excellence in health care.

Quality management has recently received a great deal of attention and the literature is expanding. There is a wide range of quality topics that fall under quality management. These topics may include, for example, quality control, quality assurance and quality 
assessment. All of which are emphasized to reach and maintain a quality system in laboratory practice [5]. It may present a challenge for medical laboratorians to implement all these programs in one system. Typically, any quality system has several essential components that include organizational structure, resources and processes. It also requires a high level of leadership and commitment to ensure quality in all processes. Laboratory personnel are critical factors to facilitate and implement a QMS in the laboratory [6]. Thus, it is important that they are knowledgeable about the quality system and well trained to comply with regulatory requirements.

It was previously reported that there is a significant correlation between the laboratory professional's attitude toward quality and their commitment [7]. Thus, laboratorians need to accept that quality management is one of their roles while working in a laboratory and they need to realize its importance in all activities. They need to be aware of the system being used in their laboratory and about all its components.

In Saudi Arabia, the organizational settings varied between laboratories. Medical laboratorians have different levels of qualifications (diploma, B.Sc., M.Sc. and Ph.D.), job titles (technician, specialist, senior specialist and consultant), years of experience and responsibilities. Is quality management actually a role for everyone or only for some? Are all laboratorians aware of the quality system and have access to the manuals and policies?

\section{Aim of the Study}

This study aims to measure the knowledge and perceptions of quality systems among medical laboratorians in Saudi Arabia. I hypothesized that all laboratories in all hospitals have a QMS to achieve accuracy and reliability. However, differences in knowledge, perception and training opportunity may exist among professionals. This difference, if it exists, may be associated with the following hypothesized variables: Job title, years of experience and qualification.

\section{Materials and Methods}

\section{Participants}

To measure the laboratorians' knowledge and perceptions about quality systems, a link to the study questionnaire was sent through a WhatsApp group. There are 200 participants in the group all of whom are laboratory professionals working in laboratories across the kingdom and normally discussing topics and issues related to the profession. The survey link was sent in March 2019 and data collection was ended in May 2019 (convenience sample). Participants were encouraged to participate and were asked to send it to their colleagues and to encourage them to participate. In addition, a link to the study questionnaire was sent via email to laboratory heads in different hospitals across the Kingdome.

Before participation, approval to conduct the study was obtained from the Health Affairs in Taif, Saudi Arabia. Informed consent from all participants was also obtained.

\section{Data collection}

A previously published and validated questionnaire was used to measure the laboratorians' knowledge and perceptions about quality systems [8]. The questionnaire has a 3-point rating scale: Agree, Disagree and I don't know. The questionnaire was administrated in both Arabic and English languages. Before administration, it was piloted on 10 laboratorians. Laboratorians were asked to attend a meeting and were asked about what they thought each item and their response meant. Translation to Arabic was done as literally as possible by the author. It was then presented to two bilingual English-Arabic speakers, both of whom speak Arabic natively, to confirm accuracy (accuracy was 98\%). The concepts being investigated in the questionnaire are easily transferred between cultures through direct translation (value-free).

\section{Data analysis}

Microsoft Excel was used for data entry. Statistical Package for the Social Sciences (SPSS) version 21 was utilized for data analysis. Descriptive statistics were used to present the demographic data and present trends in data collected.

\section{Results}

\section{Demographics}

A total of 263 medical laboratorians agreed to complete the questionnaire. Participants were 59 (22.4\%) technicians, 184 (70\%) specialists, 13 (4.9\%) senior specialists and 7 (2.7\%) consultants. One hundred sixty-six participants (63.1\%) had fewer than 5 years of experience, 47 (17.9\%) had 5 to 10 years of experience, $31(11.8 \%)$ had 10 to 15 years of experience and $19(7.2 \%)$ had more than 15 years of experience (Table 1). In addition, 27 (10.3\%) participants hold a diploma degree, 214 (81.4\%) hold a bachelor's degree, 15 (5.7\%) hold a master's degree and 7 (2.7\%) hold a Ph.D. degree (Table 2). The majority were specialists with fewer than 5 years of experience and holding a bachelor's degree. In Saudi Arabia, a diploma degree is required for a technician position, a bachelor's degree is required for a specialist position, a mas- 
ter's degree is required for a senior specialist position and a Ph.D. is required for a consultant position. However, this is subject to the availability of a position and some laboratorians may have to wait to be promoted to the appropriate position.

\begin{tabular}{|l|c|c|c|c|c|}
\hline \multirow{2}{*}{ Job title } & \multicolumn{4}{|c|}{ Qualification } & \multirow{2}{*}{ Total } \\
\cline { 2 - 5 } & Diploma & Bachelor & Master & Ph.D. & \\
\hline Technician & 26 & 33 & 0 & 0 & 59 \\
\hline Specialist & 1 & 180 & 3 & 0 & 184 \\
\hline $\begin{array}{l}\text { Senior } \\
\text { specialist }\end{array}$ & 0 & 1 & 12 & 0 & 13 \\
\hline Consultant & 0 & 0 & 0 & 7 & 7 \\
\hline Total & 27 & 214 & 15 & 7 & 263 \\
\hline
\end{tabular}

Table 1: Cross-tabulation of participants' job title and qualification.

\begin{tabular}{|l|c|c|c|c|c|}
\hline \multirow{2}{*}{ Job title } & \multicolumn{4}{|c|}{ Years of experience } & \multirow{2}{*}{ Total } \\
\cline { 2 - 5 } & $\begin{array}{c}<\mathbf{5} \\
\text { years }\end{array}$ & $\begin{array}{c}\mathbf{5 - 1 0} \\
\text { years }\end{array}$ & $\begin{array}{c}\mathbf{1 0 - 1 5} \\
\text { years }\end{array}$ & $\begin{array}{c}\mathbf{> 1 5} \\
\text { years }\end{array}$ & \\
\hline Technician & 28 & 16 & 12 & 3 & 59 \\
\hline Specialist & 129 & 30 & 13 & 12 & 184 \\
\hline $\begin{array}{l}\text { Senior } \\
\text { specialist }\end{array}$ & 9 & 2 & 2 & 1 & 13 \\
\hline Consultant & 0 & 4 & 4 & 3 & 7 \\
\hline Total & 166 & 47 & 31 & 19 & 263 \\
\hline
\end{tabular}

Table 2: Cross-tabulation of participants' job title and years of experience.

\section{Questionnaire results}

One hundred fifty-one participants (57.4\%) agreed that their laboratory has quality assurance measures based on higher performance standards of national and international organizations. The majority of participants $(176,66.9 \%)$ indicated that their quality assurance (QA) measures are guided by the system of the parent organization. For these two items, the majority of those who disagreed (74\% and 60\%, respectively) or stated their lack of knowledge ( $90 \%$ for both items) were technicians and specialists (bachelor's degree) with fewer than 5 years of experience. None of the senior specialists (master's degree) and consultants (Ph.D.) disagreed with these two items or said he/she does not know (Figure 1 and 2).

Participants believe that several factors can have an impact on meeting the QA objectives. The majority of participants agreed that the level of education, the number of years of experience, the professional credentials and the turnover rate of positions had a significant impact (90.9\%, 70\%, 73.85 and 77.2\%, respectively) (Figure 3). All consultants (Ph.D. degree) and senior specialists (master's degree) completely agreed with the impact of the level of education. Only consultants agreed completely with the number of years of experience and professional credentials. None of all groups have agreed completely with the turnover rate of positions.

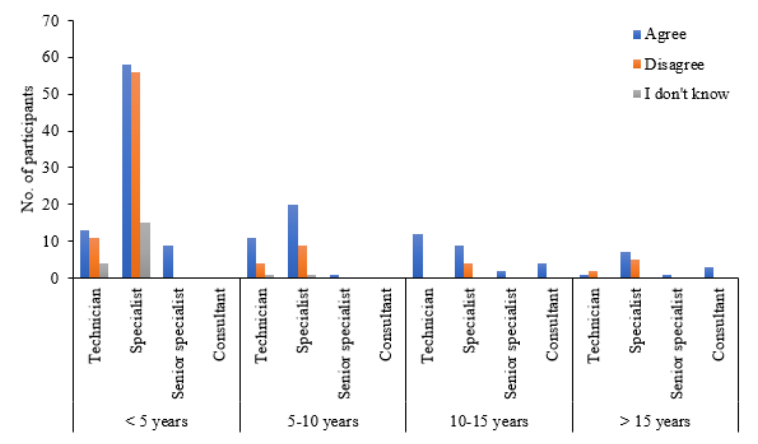

Figure 1: Participants' responses to "My laboratory has quality assurance measures based on higher performance standards of national or international organizations". Responses are grouped as (agree, disagree, I don't know) and presented in relation to job title and years of experience.

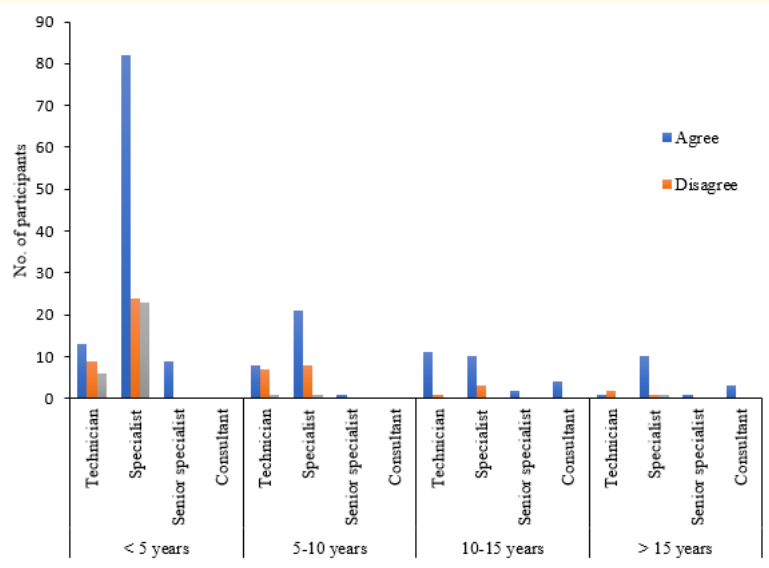

Figure 2: Participants' responses to "My laboratory has quality assurance measures guided by the quality system of the parent organization". Responses are grouped as (agree, disagree, I don't know) and presented in relation to job title and years of experience. 


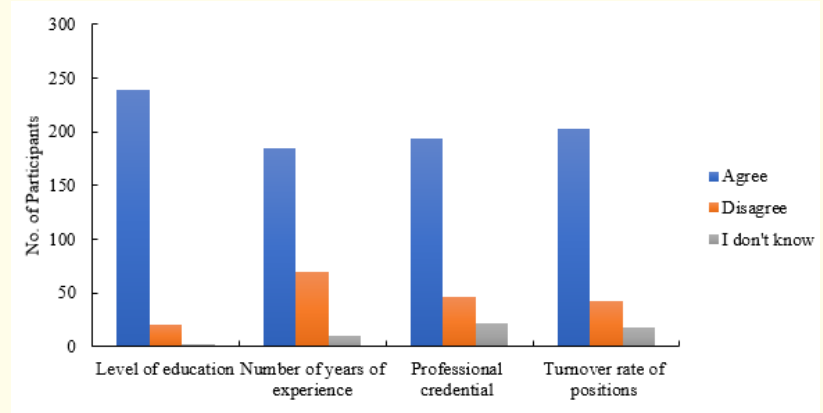

Figure 3: Participants' perception about the impact of several factors (the level of education, the number of years of experience, the professional credentials and the turnover rate of positions) on QA objectives. Responses are grouped as (agree, disagree, I don't know) and presented in relation to each factor.

One hundred fifty-six participants (59.3\%) indicated that they have a role in deciding the quality assurance measures in their laboratory. Although the majority of participants in this study were from those with fewer than 5 years of experience (166 participants), 78 participants of this group seem to have no role in quality assurance measures and 13 participants said they do not know if they have one (Figure 4).

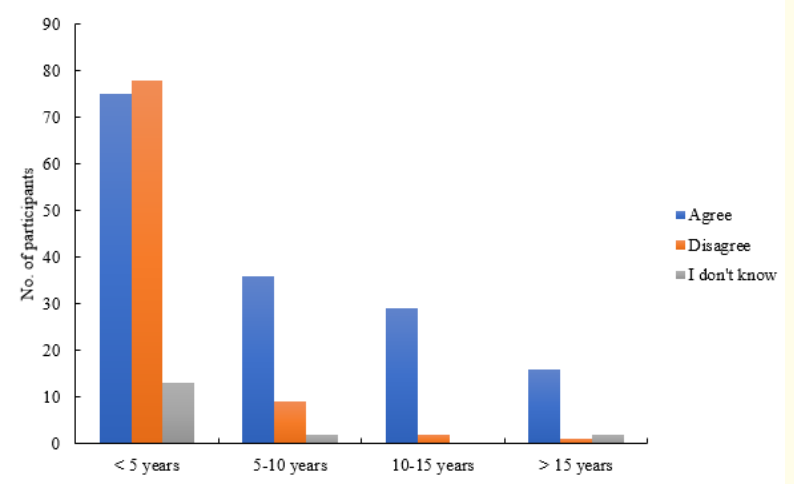

Figure 4: Participants' responses to "I myself am personally involved in deciding the quality assurance measures used in our laboratory:. Responses are grouped as (agree, disagree, I don't know) and presented in relation to years of experience.

Finally, the majority of participants (58.6\%) believe that their supervisors are knowledgeable about the clinical laboratory practice. Disagreement was seen in 81 responses (30.8\%) and lack of knowledge (I don't know) was seen in 28 responses (10.6\%). Only consultants (Ph.D. holders) agreed completely compared with other groups.

\section{Discussion}

This study was conducted to measure laboratorians' knowledge and perceptions about quality systems in their laboratory. To my knowledge, this is the first study of its kind in Saudi Arabia and may promote further studies in the future. The demographic data in this nationwide sample indicated that the majority of participants were laboratory specialists with fewer than 5 years of experience.

The data presented in this study showed that knowledge about the quality system in the laboratory increased significantly with higher job titles, more years of experience and higher qualifications $(\mathrm{P}<0.05)$. Those with job title technicians or specialists, holding a diploma or bachelor's degree and having fewer than 5 years of experience were more likely to disagree with the first and second items in the questionnaire compared with those with job title senior specialist or consultant, with higher qualifications and more experience. A similar association between knowledge about quality system and years of experience was reported in previous studies $[8,9]$

The majority of participants (57.4\%) agreed that their laboratory has a quality system based on national and international standards and the majority (66.9\%) also agreed that their system is guided by the parent organization. In accordance with international standards, there are national standards for laboratory quality and safety set by the Saudi Central Board for Accreditation of Healthcare Institutions (CBAHI) [10]. All laboratories (government or private sectors) have to comply with these standards. The difference between the number of participants who disagreed with the first item (91 participants) and with the second item (55 participants) may indicate a lack of knowledge about the existence of these national standards. The percentage of those who disagreed or do not know is perhaps worth considering by QA leadership. This may indicate that those who disagreed or did not know are disconnected from the QA system in their laboratory although they are involved in the testing process.

With regard to the impact of certain factors on meeting the QA objectives, participants with higher qualifications (master's and Ph.D.) were more likely to agree with the impact of the level of education $(\mathrm{P}<0.05)$. In Blumen., et al.'s study [8], no association between knowledge or perception of QA objectives and qualification was found. Although the majority of participants agreed that the number of years of experience, professional credentials and the turnover rate of positions have an impact, no significant differences in the pattern of responses were seen among the different groups of participants $(\mathrm{P}>0.05)$. 
While the majority of participant's perceived that they have a role in deciding the quality assurance measures, participants with more than 5 years of experience were more likely to agree. Association between experience and having a role in the QA process was previously reported $[8,9]$. Interestingly, the majority of the senior specialists (master's degree holders) in this study showed their disagreement with having a role.

Knowledge about the quality system and having a role in deciding the QA measures were mostly associated with having more than 5 years of experience. Why are those with less than 5 years of experience not knowledgeable and not involved in QA measures? These need further investigation because all medical laboratorians should be involved in QA and in deciding appropriate measures regardless of their job titles, qualifications and years of experience. Those with less than 5 years of experience can be considered as newly graduated and newly employed professionals. Thus, the adequacy of training in the undergraduate curriculum and the adequacy of training in the workplace for newly employed staff should be studied.

Although the majority of participants perceived that their supervisors are knowledgeable about the clinical laboratory practice, the number of participants who disagreed or do not know remains high (109 participants). Apart from the job title variable where consultants agreed completely, no significant differences in the pattern of responses were seen among the different groups of participants for other variables ( $\mathrm{P}>0.05)$.

\section{Conclusion}

In conclusion, this was an exploratory study to investigate medical laboratorians' knowledge and perceptions of the quality system in Saudi Arabia. The study revealed that, in general, laboratorians were knowledgeable with differences in perception related to the hypothesized variable. Further studies with a larger sample including more participants, especially from those with more years of experience, higher qualifications and job titles, may help to draw a significant conclusion. In addition, because there are different organizational settings in Saudi Arabia (Ministry of Health, military hospitals and private hospitals, private laboratories), organizational settings may be considered in future studies to identify any differences.

\section{Acknowledgments}

The author wishes to thank all participants for their time and efforts they have provided in participating in this study.

\section{Conflict of Interest}

None declared.

\section{Bibliography}

1. World Health Organization. Laboratory Quality Management System: Handbook (2011).

2. International Organization for Standardization. Quality Management Systems — Fundamentals and Vocabulary (2005).

3. Clinical and Laboratory Standards Institute. A Quality Management System Model for Laboratory Services, 5th Edition.

4. Quality Management Systems — Requirements (2015).

5. Westgard James 0 and Sten A Westgard. "Basic Quality Management Systems". Madison (WI): Westgard QC (2014).

6. Westgard J., et al. "Tietz Textbook of Clinical Chemistry and Molecular Diagnostics". Elsevier and Saunders (2006).

7. Lok Peter and John Crawford. "The Relationship between Commitment and Organizational Culture, Subculture, Leadership Style and Job Satisfaction in Organizational Change and Development". Leadership and Organization Development Journal 20.7 (1999): 365-374.

8. Blumen Steven R., et al. "Knowledge and Perceptions of Quality Systems among Vermont Laboratorians". Public Health Reports (Washington, D.C. : 1974) 125.2 (2010): 73-80.

9. K Azhar., et al. "Knowledge, Attitude and Practice of Quality Assurance Among Medical Laboratory Technologists Working in Laboratories of Lahore". Physicians Academy 6.2 (2012).

10. Saudi Central Board for Accreditation of Healthcare institution. CBAHI Standards (2019).

\section{Assets from publication with us}

- Prompt Acknowledgement after receiving the article

- Thorough Double blinded peer review

- Rapid Publication

- Issue of Publication Certificate

- High visibility of your Published work

Website: www.actascientific.com/

Submit Article: www.actascientific.com/submission.php

Email us: editor@actascientific.com

Contact us: +919182824667

\section{Funding}

None. 